\title{
Spirochaetosis of the human rectum associated with an intraepithelial mast cell and IgE plasma cell response
}

\author{
J-O GEBBERS, D J P FERGUSON, C MASON, P KELLY, AND D P JEWELL \\ From the Institute of Pathology, Kantonsspital, Luzern, Switzerland, Nuffield Department of Pathology, John \\ Radcliffe Hospital, and Gastroenterology Unit, The Radcliffe Infirmary, Oxford
}

SUMMARY In two patients presenting with mild intestinal symptoms, rectal spirochaetosis was the only morphological abnormality diagnosed by light microscopy. A re-evaluation of the morphological changes using electron microscopy and immunohistochemistry showed certain unusual features: the microorganisms were observed within epithelial cells and in subepithelial macrophages; there were numerous partially degranulated intraepithelial mast cells; and there was a marked increase in the proportion of IgE plasma cells within the lamina propria. Mucosal penetration by the organisms may be responsible for the unusual immune response. In one patient, treatment with antibiotics eliminated the spirochaetes and resulted in a clinical improvement. Spirochaetes should not always be considered as harmless commensals in the colon.

The clinical importance of intestinal spirochaetosis in man is still unresolved.' In several studies, the finding of spirochaetes attached to the human intestinal mucosa has been considered to be of no pathogenic significance, and the spirochaetes are regarded as commensals and part of the normal flora of the intestinal lumen..$^{2-6}$ In other reports, clinical symptoms, like diarrhoea, mucus discharge or rectal bleeding have been attributed to enteric spirochaetosis. $^{-9}$ In none of these studies, however, have pathological or inflammatory changes been noted in the affected mucosa.

The prevalence of spirochaetes in colonic biopsies has been reported to amount to $6.9 \%(n=144),{ }^{3}$ to $1.9 \%(n=210),{ }^{4}$ to $5 \%(n=300),{ }^{5}$ to $10 \%(n=100),{ }^{7}$ and in appendices to $7 \cdot 8 \%(\mathrm{n}=790),{ }^{3}$ to $2 \cdot 1 \%(\mathrm{n}=$ $388),{ }^{4}$ to $2 \cdot 6 \%(n=681){ }^{\circ}$

We report here two cases of patients with mild intestinal complaints in whom spirochaetosis of the rectum was diagnosed. The initial pathological examinations failed to show any mucosal abnormality. Therefore, a detailed study using electron microscopy and immunohistochemistry was undertaken to identify any changes within the rectal mucosa which could account for the clinical symptoms. In this study, we will describe the uptake of the organisms,

Address for correspondence: Jan-Olaf Gebbers, MD, Institute of Pathology, Kantonsspital, $\mathrm{CH}-60(\mathrm{X})$ Luzern. Switzerland.

Received for publication 14 August 1986. significant changes in the populations of plasma cells and the appearance of intraepithelial mast cells. These features have not been previously reported in spirochaete infestations.

\section{Case reports}

CASE 1

A 20 year old female student presented in August 1983 with three discrete attacks of diarrhoea, mild abdominal colic and nausea. She had never passed blood or mucus. In between attacks, which usually lasted four to five hours, she was asymptomatic apart from an occasional loose stool. Routine haemotological investigations and urinalysis were normal. Tests for antibodies against nuclei, smooth muscle, mitochondria, gastric parietal cells and reticulin were negative. IgG and IgA concentrations in the serum were normal, the IgM level was slightly raised. IgE concentrations were not tested. A double contrast barium enema showed no abnormality. Sigmoidoscopies in September and November 1983, and January 1984 showed a normal vascular pattern. Biopsies of the rectal mucosa were taken in September and November 1983 for histological examination (see morphological methods). The diagnosis was spirochaetosis without marked inflammatory changes in the mucosa. The patient was treated for an irritable bowel syndrome. She continued to complain 


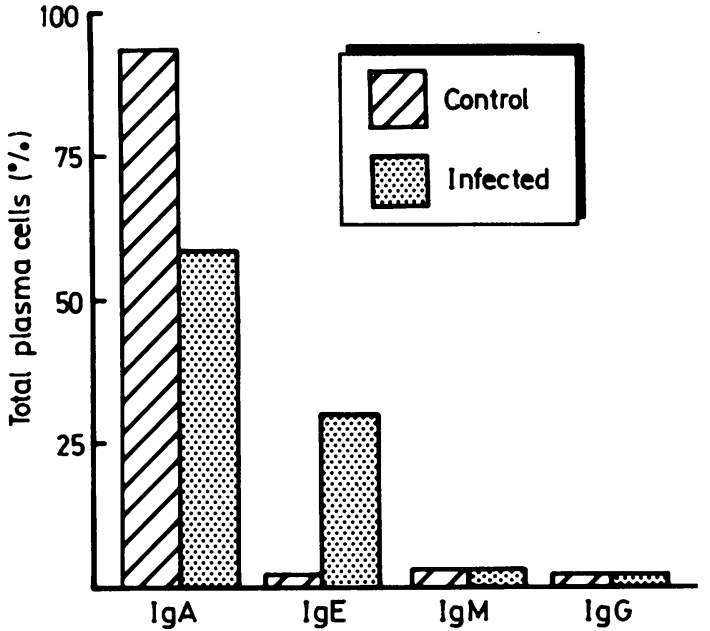

Fig. 1 Percentages of labeled plasma cells in the lamina propria mucosae of the rectal biopsies of the two cases with spirochaetosis and of five subjects with normal mucosa.

of intermittent symptoms for nine months after her first visit, but then cancelled further appointments as she was well.

CASE 2

A 74 year old woman had complained of alternating diarrhoea and constipation with some rectal bleeding in 1982. A barium enema showed diverticular disease. Symptoms settled but she was referred in 1985 with four to five loose stools daily, urgency and occasional fresh bleeding. She had lost about $6 \mathrm{~kg}$ weight over six weeks, although her appetite was good. Abdominal examination was negative and the rectal mucosa appeared normal on sigmoidoscopy. Blood count, ESR, electrolytes, proteins and liver tests were normal. Thyroid tests were also normal. A repeat barium enema confirmed diverticular disease. Histology of the rectal biopsy showed spirochaetosis (see morphological methods). She was initially treated as an irritable bowel syndrome with lorazepam, mebeverine, and regulan. Diarrhoea became more severe and she lost more weight. Metronidazole $200 \mathrm{mg} /$ eight hourly was begun. She was admitted to hospital with eight to 10 liquid stools daily. No pathogens were isolated from stool and Clostridium difficile toxin was absent. Colonoscopy was performed which showed a normal mucosa and sigmoid diverticula. A second biopsy was taken 10 days and a third biopsy four months post-treatment. Symptoms settled and she has remained well.

\section{Methods}

Tissue from all biopsies was processed for histo-

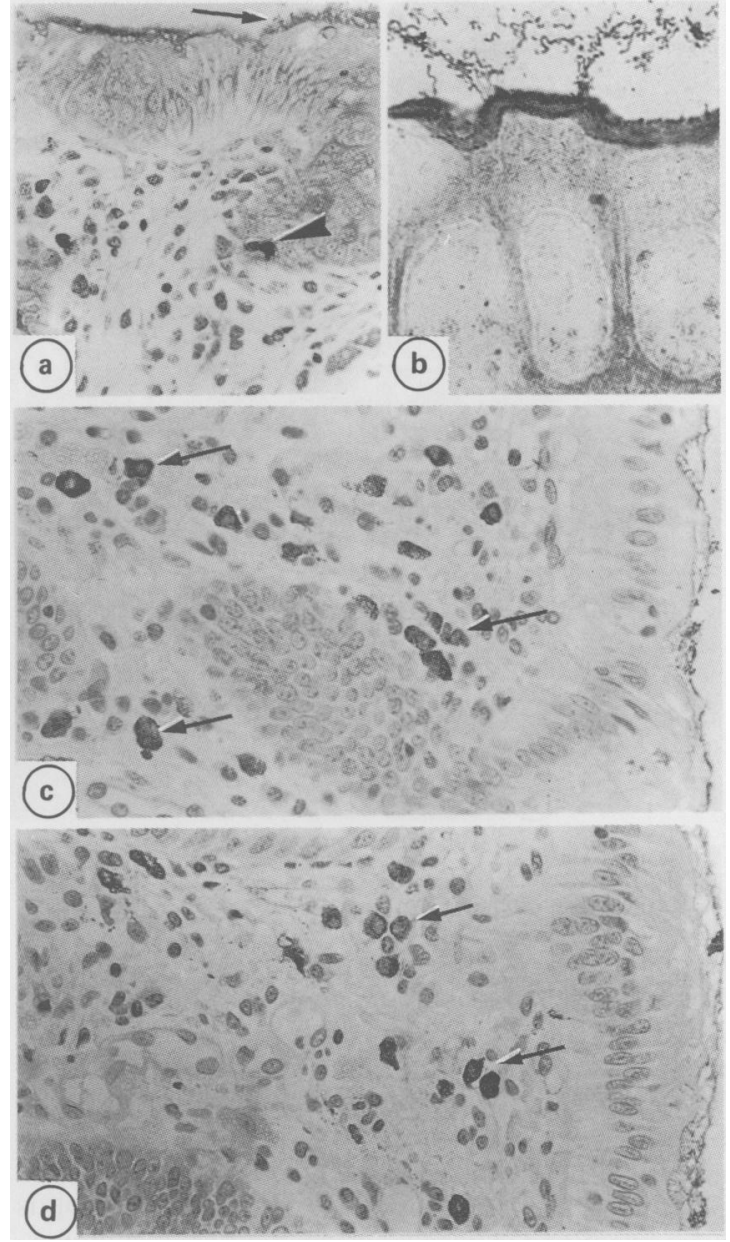

Fig. 2 Light micrographs through the rectal mucosa. (a) The mucosal morphology with areas of dense surface staining showing the location of the spirochaetes (arrow) and intraepithelial mast cells (arrow head) is illustrated. Giemsa stained. (b) Fusiform microorganisms are identifiable both on the epithelial cells and within the lumen by Dieterle's stain. (c) Section stained immunocytochemically with IgA antibodies showing the positive cells within the lamina propria (arrows). (d) Section treated with IgE antibodies showing the numerous positively stained cells (arrows).

logical examinations using standard techniques. The sections were stained with haematoxylin and eosin, Giemsa, and Dieterle's stain." This latter staining method involves a double impregnation with uranyl nitrate and silver nitrate resulting in dark brown to black staining of spirochaetes (and some bacteria). Tissue was also processed for both, transmission and scanning electron microscopy, using standard techniques. The immunohistochemical examination of the various classes of plasma cells was carried out on sections from the tissues processed for histology 

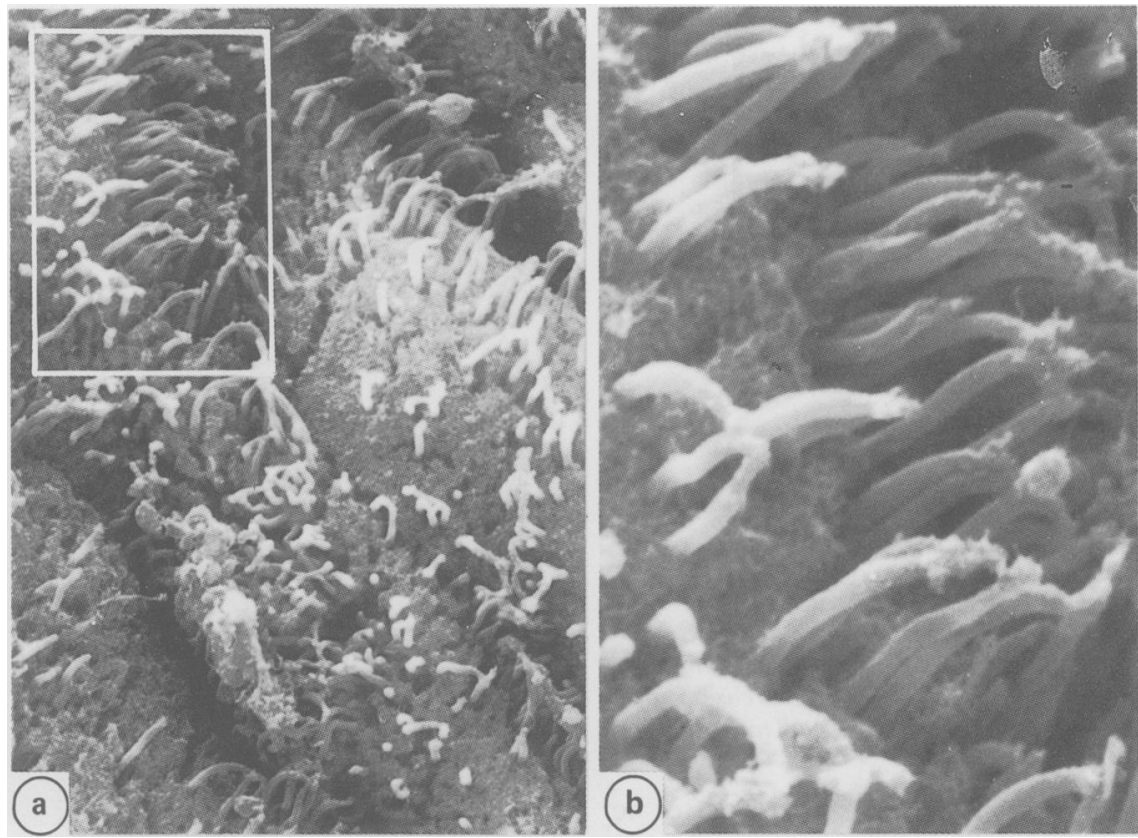

Fig. 3 Scanning electron micrograph of the mucosal surface of the rectum showing groups of spirochaetes attached to epithelial cells. (b) Detail of the spirochaetes from the area marked in (a).

using the peroxidase antiperoxidase (PAP) method. The following antisera against human Ig were used; anti-IgA, -IgG, -IgM (Dakopatts, Copenhagen, Denmark) and anti-IgE (Behring Institute, Marburg, West Germany). For comparison, samples of rectal biopsies from five symptomatic subjects for whom no abnormalities could be identified, and from six patients with Crohn's disease or ulcerative colitis were examined in parallel using identical techniques. Quantification was based on counting all stained cells in serial sections (about 1500 plasma cells per biopsy specimen). The number of cells in each class was obtained by counting the positive stained cells in serial sections incubated with one of the four specific antihuman Ig sera. The counts are presented as percentages of the total plasma cells population (Fig. 1). Intraepithelial mast cells were counted in Giemsa stained paraffin sections.

\section{Results}

HISTOLOGY

The histological findings were essentially similar in the specimens from both cases. The surface epithelium and the crypt architecture were normal comprising columnar epithelial and goblet cells. There was no goblet cell depletion and only a slight focal increase of mononuclear cells in the lamina propria mucosae. The only significant histological abnormality was scattered basophilic areas of the brush border of the surface epithelium (Fig. 2). The Dieterle's stain more readily showed the fusiform organisms attached to the surface epithelium and in several crypt mouths indicating intestinal spirochaetosis (Fig. 2).

\section{ELECTRON MICROSCOPY}

The ultrastructural observations were similar in both patients. Numerous spiral microorganisms were observed attached to the luminal surface of the superficial epithelium and the neck of the crypts (Figs. 3 and 4). The spirochaete infestation was more dense in case 2. Both absorptive and goblet cells were affected. Their microvilli were depleted proportional to the density of the attached microorganisms. The ultrastructural features of the microorganisms were essentially the same as has been described in previous reports on spirochaete infestation of the human intestine. . $^{-711}$

In a detailed examination of the epithelium, a number of spirochaetes were found within vacuoles and lysosomes in the apical cytoplasm of the epithelial cells together with numerous electron lucent vesicles and ' $R$ bodies" ${ }^{\prime \prime 2}$ (Fig. 4). These cells showed no degenerative or necrobiotic changes. In addition, spirochaetes were observed either singly or in groups within lysosomes of macrophages present in the lamina propria (Fig. 5). The majority of 


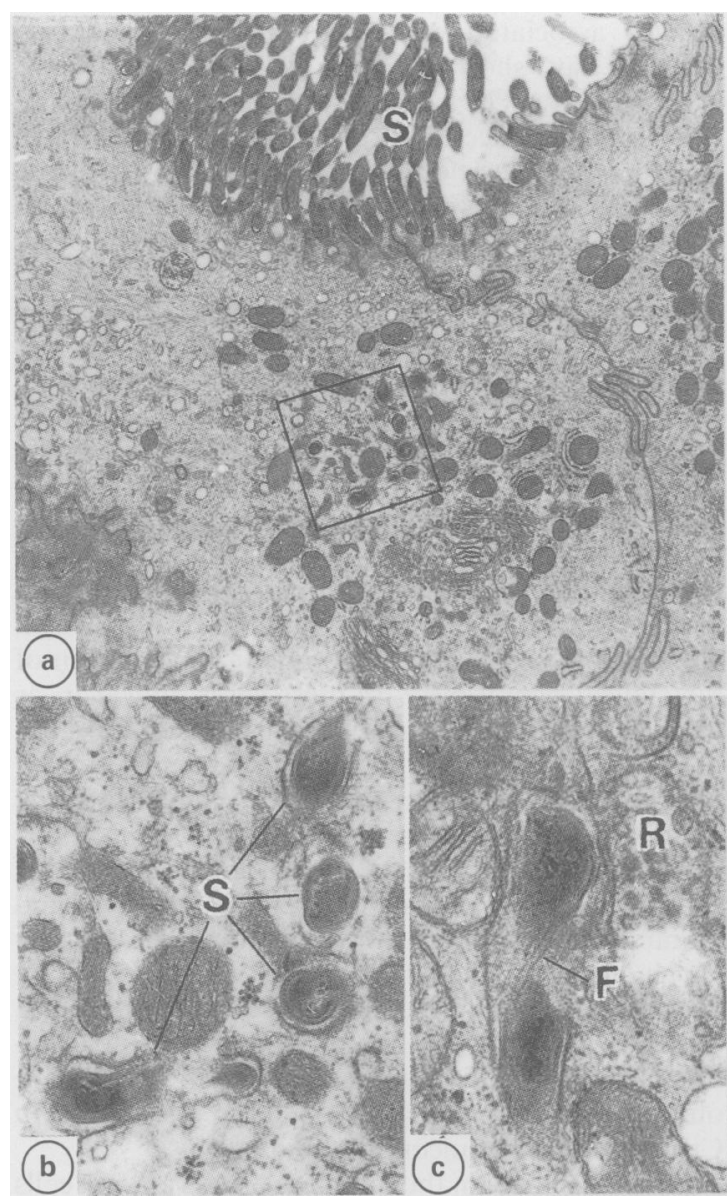

Fig 4 (a) Transmission electron micrograph (TEM) showing many spirochaetes $(S)$ attached to the luminal surface of the epithelial cell and depletion of microvilli. (b) Detail of the area outlined in (a) showing a number of spirochaetes $(S)$ in the epithelial cell cytoplasm enclosed within vacuoles. (c) Enlargement of an intracytoplasmic spirochaete showing the longitudinally running axial fibrils (F). $R-R$ body.

macrophages showed signs of activation with numerous primary and secondary lysosomes.

A number of mast cells were present within the epithelium of the crypts (Fig. 6). Several of these cells were partially degranulated and a number possessed a large vacuole which was limited by an extensively folded membrane (Fig. 6). The intraepithelial mast cells were situated in all compartments of the crypts; on average two to three cells per crypt were observed. This is in marked contrast with the finding in the five control biopsy specimens from normal rectal mucosa and from six patients with Crohn's disease or ulcerative colitis where an extensive search failed to identify any intraepithelial mast cells.

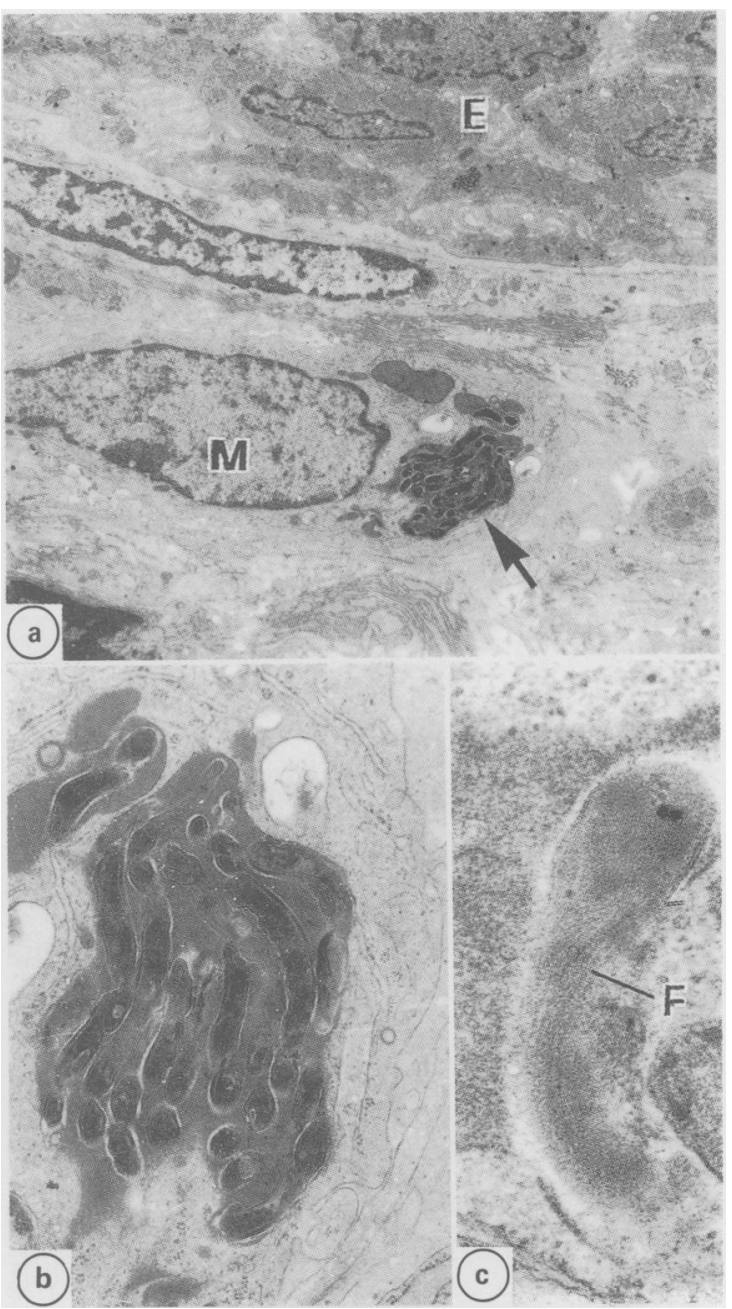

Fig. 5 TEM showing a macrophage $(M)$ with a large phagosome containing spirochaetes (arrow) within the lamina propria. E-epithelium. (b) Detail of the phagosome containing spirochaetes arrowed in (a). (c) Spirochaete within a macrophage phagosome showing the axial fibrils $(F)$.

In case 2, ultrastructural examination of the biopsies at 10 days and four months after treatment confirmed the absence of spirochaetes on the luminal surface. Intraepithelial mast cells were extremely rare.

\section{IMMUNOHISTOCHEMISTRY}

Numerous plasma cells were present within the lamina propria. Cells producing specific classes of Ig were identified by the dense brown immunocytochemical reaction product (Fig. 2). Quantification of the four Ig classes of plasma cells showed increased 


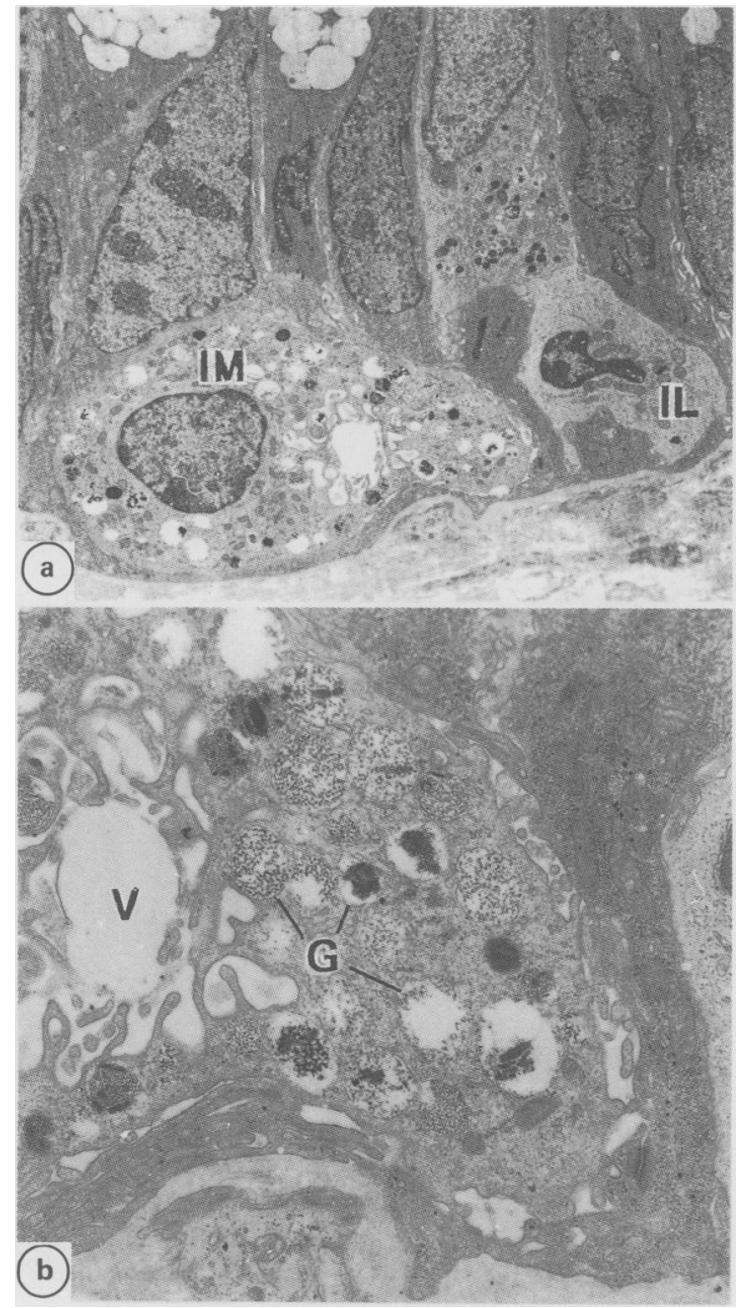

Fig. 6 TEM from the crypt region showing a partially degranulated mast cell (IM) and an intraepithelial lymphocyte (IL). (b) Detail of the IM showing the numerous cytoplasmic granules $(G)$ and a large vacuole $(V)$ limited by an extensively folded membrane.

numbers of IgE positive cells in both cases when compared with controls (Fig. 1). In case 2, the biopsies taken after treatment showed a marked decrease in the number of IgE cells (Fig. 1).

\section{Discussion}

From a survey of the literature it is unclear whether intestinal spirochaetes always behave as harmless commensals or whether they may be pathogenic under certain conditions. ${ }^{1-411}$ In the majority of studies the organisms appear to be non-pathogenic and extensive surveys of the incidence of spiro- chaetes associated with the normal and diseased intestine have shown that spirochaetosis per se does not result in specific clinical symptoms. ${ }^{2-b}$

In rare instances, Takeuchi $e^{2} a l^{4}$ found spirochaetes within vesicles in colonic epithelial cells, free in the intercellular space between epithelial cells, and in the lamina propria contained in phagosomes within macrophages. The authors noticed no inflammatory response in the lamina propria, but they assumed that spirochaetes when invading the gut mucosa of human subjects in massive numbers could be able to produce structural alterations in host tissues and clinical symptoms. ${ }^{4}$

In fact, there have been a few reports of patients with clinical symptoms in which the only abnormal feature was the presence of large numbers of intestinal spirochaetes. ${ }^{7-9}$ It has also been shown, in some cases, that treatment with antibiotics which eliminate the spirochaetes results in a resolution of the clinical symptoms. ${ }^{7-9}$ In these cases, however, as in the asymptomatic infestations, there were no obvious pathological or inflammatory changes which could explain the clinical symptoms. Similarly in the two cases examined in the present study, no obvious abnormality was detected by routine histology. Further examination using electron microscopy and immunohistochemistry, however, identified significant changes in the rectal mucosa in both patients. The changes involved increases in the number of $\operatorname{IgE}$ positive plasma cells and the appearance of intraepithelial mast cells. Neither of these findings were observed in the normal colon or in patients with Crohn's disease or ulcerative colitis. ${ }^{13-16}$

Local increases in the numbers of IgE plasma cells have been reported in 'allergic proctitis', ${ }^{17}$ and in infestations with helminth parasites. ${ }^{18}$ In the latter condition, there is also a striking hyperplasia of the mucosal mast cells. ${ }^{14-21}$ It is probable that these two factors are interrelated, because it is known that IgE and mast cells are associated with immediate type hypersensitivity and are important in the host's immune response to parasites. ${ }^{18-21}$

In the absence of any other identifiable factors we would propose that the spirochaetes are responsible for this immune response and appear to act as intestinal parasites. This is consistent with our observations that in the patient treated with antibiotics the elimination of the spirochaetes and the reappearance of the normal immune response is associated with a clinical improvement. Because these changes have not been examined in previous studies it is impossible to tell how often they occur or if there is any correlation with cases exhibiting clinical symptoms.

It is well known that organisms normally considered to be harmless commensals can become patho- 
genic under certain circumstances. It is possible that such a change in the host-parasite relationship has occurred in the two cases described here. In the previous studies emphasis was placed on the fact that the spirochaetes were limited to the intestinal lumen with no penetration of the mucosa. ${ }^{235-711}$ In both of our patients, however, there was uptake of the spirochetes into the epithelial cells and the macrophages of the lamina propria. This finding is similar to that described by Takeuchi $e t a l,{ }^{4}$ and for a patient with Crohn's disease..$^{22}$ It is possible that this breaching of the mucosal barrier is responsible for the immune response and the clinical symptoms. This would be consistent with observations in animals. In the mouse and monkey, there is no mucosal invasion and the infestations are non-pathogenic while in the pig, swine dysentery is associated with mucosal invasion. ${ }^{23}$

In conclusion, it is proposed that the breakdown in the normal host-parasite relationship is responsible for the immune response seen in the patients in this study and that these changes may explain the clinical symptoms. It would appear, therefore, that although spirochaetes normally behave as commensals they may be capable of becoming pathogenic under certain circumstances.

We thank Mrs D Harrison, Ms S Patel, Mrs M Rychetnik, Mrs Y Smart and Mr A Skinner for technical help.

\section{References}

1 Anonymous. Intestinal spirochaetes. [Editorial] Lancet 1984; i: 720 .

2 Gear EV, Dobbins WO III. Rectal biopsy: a review of its diagnostic usefulness. Gastroenterology 1968; 55: 522-44.

3 Lee FD, Kraszewski A, Gordon J, Howie JGR, McSeveney D, Harland WA. Intestinal spirochaetosis. Gut 1971; 12: 126-33.

4 Takeuchi A, Jervis HR, Nakazawa H, Robinson DM. Spiral-shaped organisms on the surface colonic epithelium of the monkey and man. Am J Clin Nutr 1974; 27: 1287-96.

5 Henrik-Nielsen R, Orholm M, Pedersen JO, HovindHougen K, Teglbjaerg PS, Thaysen EH. Colorectal spirochetosis: clinical significance of the infestation. Gastroenterology 1983; 85: 62-7.

6 Henrik-Nielsen R, Lundbeck FA, Teglbjaerg PS,
Ginnerup P, Hovind-Hougen K. Intestinal spirochetosis of the vermiform appendix. Gastroenterology 1985; 88: 971-7.

7 Harland WA, Lee FD. Intestinal spirochaetosis. $\mathrm{Br} \mathrm{Med}$ $J$ 1967; 3: 718-9.

$8 \mathrm{Gad} \mathrm{A}$, Willén R, Furugard Ket al. Intestinal spirochaetosis as a cause of longstanding diarrhoea. Upsala J Med Sci 1977; 82: 49-54.

9 Douglas JG, Crucioli V. Spirochaetosis: a remediable cause of diarrhoea and rectal bleeding? Br Med J 1981; 283: 1362-3.

10 Van Orden AE, Greer PW. Modification of the Dieterle spirochete stain. J Histotechnol 1977; 1: 51-3.

11 Crucioli V, Busuttil A. Human intestinal spirochaetosis. Scand J Gastroenterol 1981; 70: suppl: 177-9.

12 Stone J, Mukherjee TM, Hecker R. C bodies and R bodies in the epithelial cells of normal and diseased human rectum. Arch Pathol Lab Med 1977; 101: 437-41.

13 Norris HT, Zamcheck N, Gottlieb LS. The presence and distribution of mast cells in the human gastrointestinal tract at autopsy. Gastroenterology $1963 ; 44$ : 448-55.

14 Baklien K, Brandtzaeg P. Comparative mapping of the local distribution of immunoglobulin-containing cells in ulcerative colitis and Crohn's disease of the colon. Clin Exp Immunol 1975; 22: 197-209.

15 Gebbers J-O, Otto HF. Immunohistochemical and electron microscopic observations on the local immune response in ulcerative colitis. Virchows Arch [Pathol Anat] 1977; 374: 271-3.

16 Gebbers J-O. Colitis ulcerosa: Immun-und Ultrastrukturpathologie. Stuttgart - New York: Thieme, 1981.

17 Rosekrans PCM, Meijer CJLM, van der Wal AM, Lindeman J. Allergic proctitis, a clinical and immunopathological entity. Gut 1980; 21: 1017-23.

18 Jarrett EEE. Immunoregulation of IgE responses: the role of the gut in perspective. Ann Allergy 1984; 53: 550-6.

19 Mayrhofer G. Sites of synthesis and localization of $\operatorname{IgE}$ in rats infested with Nippostrongylus brasiliensis. In: Immunology of the gut. Ciba Foundation Symposium 46. Amsterdam: Elsevier, 1977: 155-82.

20 Lemanske RF, Atkins FM, Metcalfe DD. Gastrointestinal mast cells in health and disease. Part II. $J$ Pediatr 1983; 103: 343-51.

21 Jarrett EEE, Haig DM. Mucosal mast cells in vivo and in vitro. Immunol Today 1984; 5: 115-9.

22 Antonakopoulos G, Newman J, Wikinson M. Intestinal spirochaetosis: an electron microscopic study of an unusual case. Histopathology 1982; 6: 477-88.

23 Harris DL, Kinyon JM. Significance of anaerobic spirochetes in the intestines of animals. Am J Clin Nutr 1974; 27: $1297-304$. 